\title{
Implementing Self Sustained Quality Control Procedures in a Clinical Laboratory
}

\author{
Roshan Khatri,' Sanjay KC,' Prabodh Shrestha,' JN Sinha' \\ ${ }^{1}$ College of Medical Sciences Teaching Hospital, Bharatpur, Chitwan, Nepal.
}

\section{ABSTRACT}

Introduction: Quality control is an essential component in every clinical laboratory which maintains the excellence of laboratory standards, supplementing to proper disease diagnosis, patient care and resulting in overall strengthening of health care system. Numerous quality control schemes are available, with combinations of procedures, most of which are tedious, time consuming and can be "too technical" whereas commercially available quality control materials can be expensive especially for laboratories in developing nations like Nepal. Here, we present a procedure performed at our centre with self prepared control serum and use of simple statistical tools for quality assurance.

Methods: The pooled serum was prepared as per guidelines for preparation of stabilized liquid quality control serum from human sera. Internal Quality Assessment was performed on this sample, on a daily basis which included measurement of 12 routine biochemical parameters. The results were plotted on Levey-Jennings charts and analysed with quality control rules, for a period of one month.

Results: The mean levels of biochemical analytes in self prepared control serum were within normal physiological range. This serum was evaluated every day along with patients' samples. The results obtained were plotted on control charts and analysed using common quality control rules to identify possible systematic and random errors. Immediate mitigation measures were taken and the dispatch of erroneous reports was avoided.

Conclusions: In this study we try to highlight on a simple internal quality control procedure which can be performed by laboratories, with minimum technology, expenditure, and expertise and improve reliability and validity of the test reports.

Keywords: Levey-Jennings charts; pooled sera; quality control; Westgard Rule.

\section{INTRODUCTION}

Verification of laboratory standards is done through the process of accreditation which is in turn relies on its results. Laboratories can be assessed on their three phases of functioning, Pre-analytical, analytical and post analytical phases. ${ }^{1}$ While pre-analytical and postanalytical errors are more managerial issues, Internal Quality Control (IOC) and External Quality Assessment (EQA) schemes can monitor the analytical variability (both imprecision and inaccuracy). ${ }^{2}$
Numerous papers have been written to show which combinations of procedures, protocols are optimal for detecting errors, variations, shifts, random errors, and trends across the assay batch. ${ }^{3}$ In the vast array of technical jargons, statistical puzzles, these quality control procedures are tedious, time consuming,

Correspondence: Dr. Roshan Khatri, College of Medical Sciences Teaching Hospital, Bharatpur, Chitwan, Nepal. Email: roshankhatri@ gmail.com, Phone: 9851131822. 
expensive and can be "too technical" especially for small and middle scaled laboratories. ${ }^{4}$

In this study we try to highlight on a simple quality control procedure that can be run by laboratories on a small scale, with minimum technology and yet improve reliability and validity of their test reports.

\section{METHODS}

This study is a prospective analytical study, performed in the Clinical Laboratory of College of Medical Sciences Teaching Hospital. IOC tests were performed based on biochemical tests from the pooled sera, run every day for a month from $1^{\text {st }}$ August 2012 to $31^{\text {st }}$ August 2012.

Pooled Sera Preparation: The pooled serum for quality control was prepared as per World Health Organisation (WHO) recommended protocol for preparation of stabilized liquid quality control serum to be used in clinical chemistry with some modifications. ${ }^{2,5,6}$ One major adaptation is on the use of serum of patients instead that of healthy individuals for preparation of pooled serum. After collection, the sera was mixed properly for complete homogeneity, screening was done for HBsAg, Anti-HCV antibodies and Anti-HIV antibodies using commercially available kits. This sera was divided into forty different aliquots, one $\mathrm{ml}$ each stored at -8 degrees for future use.

Each of this liquid control serum was thawed completely every morning, and tests were run as a new lot of normal control on Hitachi 902 Automatic Analyzer $\left({ }^{\circledR} \mathrm{ROCHE}\right)$ and HumaLyte Plus 3, Ion-Selective Electrolyte Analyzer for analysis of the following 12 routinely analyzed constituents on the instruments (Table 1). Test parameters were chosen on the basis of frequency, test methods, including both enzymatic and non enzymatic procedures and electrolytes.

\begin{tabular}{|ccc|}
\hline \multicolumn{3}{|l|}{ Table 1. List of biochemical parameters analysed in the } \\
control serum. & & \\
\hline Non-Enzymatic & Enzymatic & Electrolytes \\
Glucose & SGOT & Sodium \\
Urea & SGPT & Potassium \\
Creatinine & ALP & \\
Uric Acid & Amylase & \\
TG & & \\
Cholesterol & & \\
\hline
\end{tabular}

ALP-Alkaline Phosphatase, SGOT-Serum Glutamic Oxaloacetic Transaminase, SGPT-Serum Glutamic Pyruvic Transaminase, TG- Triglycerides.

All the reports obtained from the test procedure (IQC) were entered in Excel 2007. Quality control charts, Levey-Jennings (LJ) chart were plotted every day and analysed using Westgard Rule (modified) for quality control. Comparison was done across the mean value, 1, 2 and 3 Standard Deviation and thence interpreted. ${ }^{7,8}$

\section{RESULTS}

The biochemical parameters of locally prepared control sera obtained through-out the month were analysed for their distribution. Levey-Jennings control charts and Westgard Rule are the commonly employed, well understood quality control procedures which are possible only with normally distributed data and give rise to a wide range of possible control charts that can be further used..$^{2,3}$ For our IOC we consider common QC rules (Table 2). Mean, standard deviation (SD), and co-efficient of variation (CV) of the 12 measured biochemical parameters were calculated for 31 days (Table 3). 
Roshan et al. Implementing Self Sustained Quality Control Procedures in a Clinical Laboratory

\begin{tabular}{|c|c|c|c|}
\hline Rule & Definition & Type of error detected & Inference \\
\hline $1-2 s$ & $\begin{array}{l}\text { A single control observation is } \\
\text { outside the } \pm 2 \text { s limit }\end{array}$ & $\begin{array}{l}\text { Warning to look for other rule } \\
\text { violations }\end{array}$ & $\begin{array}{l}\text { Patients report can be } \\
\text { reported }\end{array}$ \\
\hline $1-3 s$ & Any control result outside $\pm 3 s$ & $\begin{array}{l}\text { Identifies unacceptable random } \\
\text { error or possibly the beginning } \\
\text { of a large systematic error }\end{array}$ & $\begin{array}{l}\text { Re-test patient and } \mathrm{OC} \\
\text { samples }\end{array}$ \\
\hline $2-2 s$ & $\begin{array}{l}\text { Two consecutive } \mathrm{OC} \text { results, } \\
\text { greater than } 2 \mathrm{~s} \text {, on the same side } \\
\text { of the mean }\end{array}$ & Identifies systematic error & $\begin{array}{l}\text { Re-test patient and } \mathrm{OC} \\
\text { samples }\end{array}$ \\
\hline $\mathrm{R}-4 \mathrm{~s}$ & $\begin{array}{l}\text { There is at least a } 4 \text { s difference } \\
\text { between control values within a } \\
\text { single run }\end{array}$ & Identifies random error & $\begin{array}{l}\text { Re-test patient and } \mathrm{OC} \\
\text { samples }\end{array}$ \\
\hline $3-1 \mathrm{~s}$ or $4-1 \mathrm{~s}$ & $\begin{array}{l}3 \text { or } 4 \text { consecutive results greater } \\
\text { than } 1 \mathrm{~s} \text {, on the same side of the } \\
\text { mean }\end{array}$ & Identifies systematic error & $\begin{array}{l}\text { Warning for maintenance } \\
\text { of the system, if in control } \\
\text { can be reported }\end{array}$ \\
\hline $10 x$ & $\begin{array}{l}7 \text { or } 8 \text {, or } 9 \text {, or } 10 \text {, or } 12 \text { control } \\
\text { results on the same side of the } \\
\text { mean regardless of the specific } \\
\text { SD in which they are located }\end{array}$ & Identifies systematic error & $\begin{array}{l}\text { Warning for maintenance } \\
\text { of the system, if in control } \\
\text { can be reported }\end{array}$ \\
\hline
\end{tabular}

\begin{tabular}{|c|c|c|c|c|}
\hline Analytes & Mean & Standard Deviation & CV (\%) & Reference Range \\
\hline Glucose(R) & 102 & 2.07 & 0.02 & $70-140 \mathrm{mg} / \mathrm{dl}$ \\
\hline Urea & 50 & 3.60 & 0.07 & $15-40 \mathrm{mg} / \mathrm{dl}$ \\
\hline Creatinine & 1.1 & 0.21 & 0.19 & $0.6-1.5 \mathrm{mg} / \mathrm{dl}$ \\
\hline Uric Acid & 5.2 & 0.40 & 0.08 & $3.5-7.2 \mathrm{mg} / \mathrm{dl}$ \\
\hline TG & 131 & 15.4 & 0.12 & $40-170 \mathrm{mg} / \mathrm{dl}$ \\
\hline Cholesterol & 129 & 6.8 & 0.05 & $130-240 \mathrm{mg} / \mathrm{dl}$ \\
\hline Sodium & 144 & 2.94 & 0.02 & $135-145 \mathrm{mEq} / \mathrm{L}$ \\
\hline Potassium & 4.1 & 0.22 & 0.05 & $3.5-4.5 \mathrm{mEq} / \mathrm{L}$ \\
\hline SGOT & 29 & 4.07 & 0.14 & $<38 \mathrm{U} / \mathrm{L}$ \\
\hline SGPT & 14 & 3.84 & 0.27 & $<41 \mathrm{U} / \mathrm{L}$ \\
\hline ALP & 128 & 21.73 & 0.17 & $56-306 \mathrm{U} / \mathrm{L}$ \\
\hline Amylase & 81 & 17.3 & 0.21 & $28-100 \mathrm{U} / \mathrm{L}$ \\
\hline
\end{tabular}




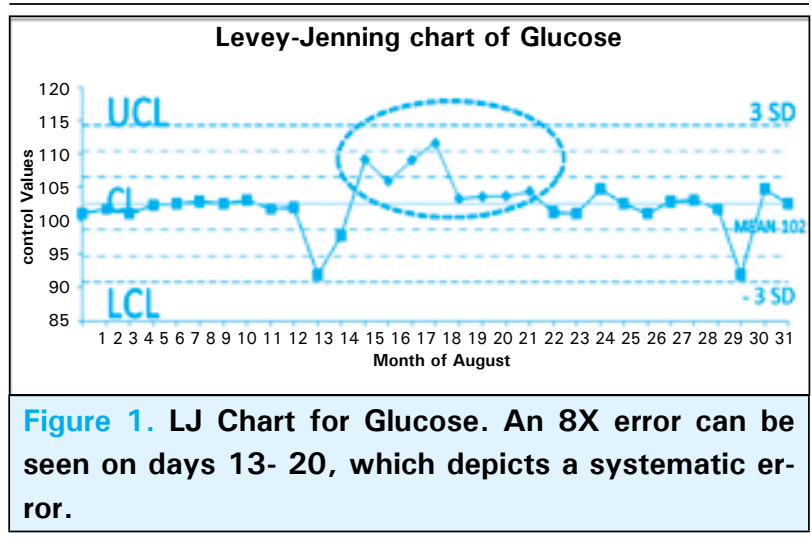

LJ charts for Glucose, Uric Acid, Sodium and ALP (Figures 1-4) have been chosen here to demonstrate typical cases of errors detected including a normal standard LJ chart.

LJ chart of Glucose demonstrates 8X error starting from day 13 to day 20 where all the values are on the same side of the mean $(102 \mathrm{mg} / \mathrm{dl})$ regardless of the specific SD in which they are located (Figure 1). This depicts a systemic error in our system, which is a warning for maintenance of the system, and which if is in control, patients' reports on those days can be reported otherwise reports should be discarded and tests re-run after proper maintenance.

LJ chart of uric acid depicts violation of 3-1s rule consecutive results lesser than $1 \mathrm{~s}$, on the same side of the mean on days 7-9, where the consecutive results are lesser than the mean-1s value (5.2-0.40). This denotes a systematic error, warning for maintenance of the system, reports of that day can be dispatched if the system in under control (Figure 2).

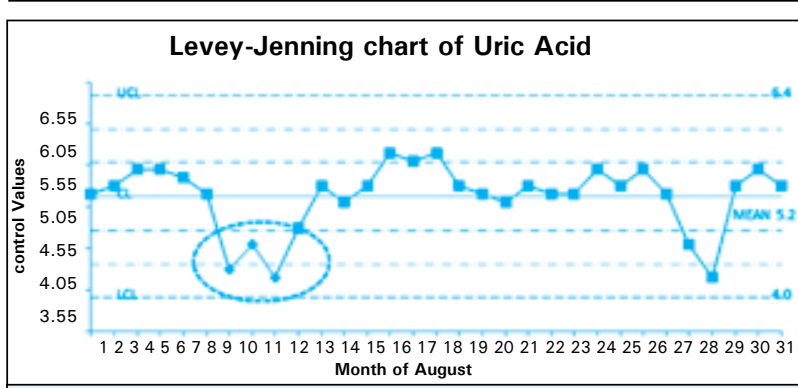

Figure 2.LJ chart of uric acid. Violation of 3-1s rule. This denotes a systematic error, warning for maintenance of the system, reports of that day can be dispatched only if the system in under control and stable.

LJ chart of Sodium shows a normal appropriate control chart where no rules of the modified Westgard Rule 1989, has been violated during the entire month. Single values outside 2 SDs as on day 6 and 26 show warning errors, and depending upon the degree of accuracy required can be accepted. In a stable system, 1-2s rule can be regarded as a warning because $95 \%$ of the reports will fall between \pm 2 SDs of mean (Figure 3 ).

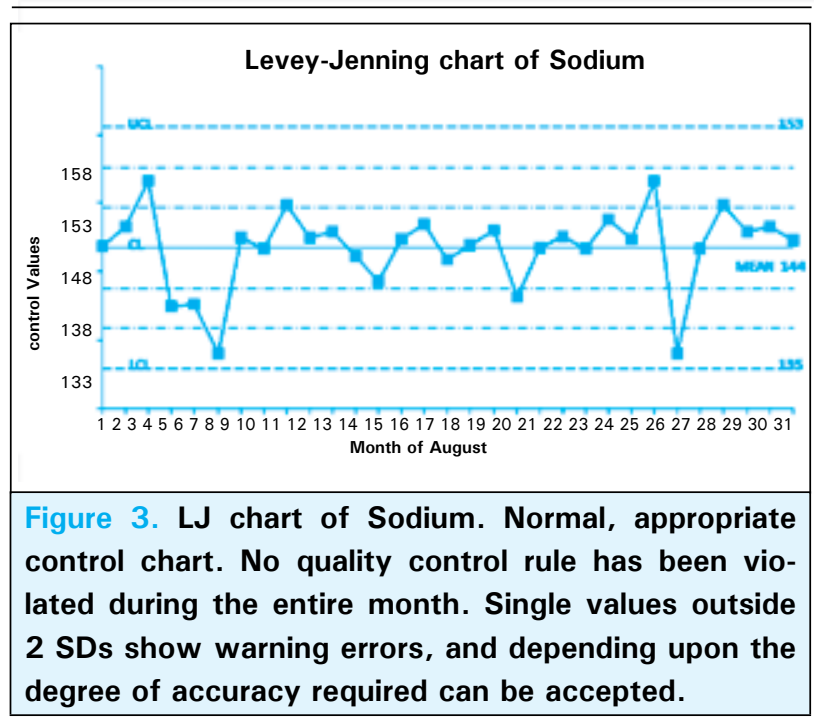

LJ chart of ALP displays violation of 1 -3s rule on day 10. A single result beyond $-3 S D$ generally denotes a random error or a significant systematic change. Test results should be rejected on that particular day, and reassessed for source any random error if no significant changes in system have been done (Figure 4).

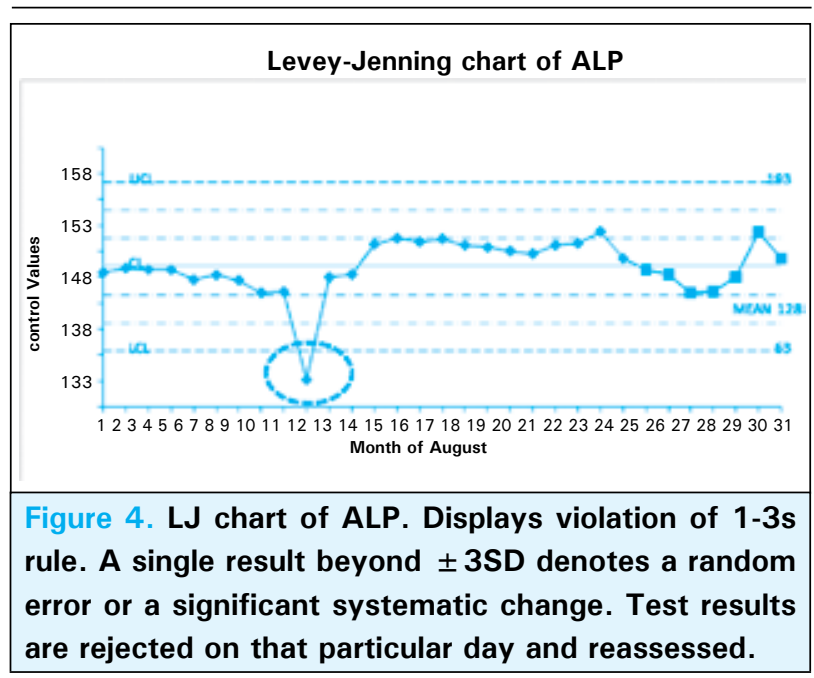

\section{DISCUSSION}

WHO (1981) has defined IOC as procedures undertaken by the staff of a laboratory to assess laboratory work and the emergent results, in order to decide whether they are reliable enough to be released which control the laboratory outputs. ${ }^{9}$ Despite the 
well accepted importance of IQC program for every clinical laboratory, laboratories in many developing nations are disadvantaged because of high cost of imported commercial quality-control materials and lack of expertise needed.

In our country, previous studies have shown that QC procedures are not practiced in majority of the centres. Here, clinical laboratories are overwhelmed by huge burden of workload. Inadequacy of knowledge, high cost of control materials and complexity of procedures are major obstacles for good laboratory practice. Commercially available quality control materials have to be imported from abroad. ${ }^{10,11}$

This study demonstrates how a homemade control material can be used for QC procedures. It also demonstrates a simple method of interpreting and analysing the output to guarantee the validity and reliability of the system. Preparation of pooled serum is easy, inexpensive and can be done even at small scaled centres and by the use of simple statistical tools, a very comprehensive quality control can be achieved. This also avoids the complexities, sources of errors associated with pre-analytical and post-analytical handling of commercial controls.

Our procedure simply relies on $\pm 2 \mathrm{SD}$, comparison along with the mean, this procedure allows us to monitor our system but it does not allow us to calculate Total error or bias of our system. Some of the clinically significant errors can still be missed, and misleading patient results can be reported if our system as a whole is not functioning properly, and our mean is far from the true value to be reported.

According to WHO protocol for preparation of stabilized liquid quality control serum, it is recommended to extract serum from blood of healthy volunteer. However, this recommendation was not feasible in our context due to the scarcity of fresh blood from healthy individuals. We instead used serum of patients visiting our lab for investigations. Quality control procedure is a continuous process which should be run every day as a routine practice; but here we are only able to present a month's scenario. One of our other limitations is the lack of authentication of QC procedures by comparing with external quality control programs and commercially available kits.

\section{CONCLUSIONS}

This quality control procedure demonstrates that quality control practices can be performed on small scale with minimum technology, expertise, expenditure and within minimum time frame. Integrating simple control procedures into practice can lead to strengthening of laboratory services and overall better health care system, especially in a resource deprived nation like Nepal. Such practices should be encouraged to be conducted in a routine basis in every clinical laboratory of Nepal.

\section{ACKNOWLEDGEMENTS}

Binay Tara Foundation, Technicians and laboratory staffs of College of Medical Sciences Teaching Hospital, Bharatpur, Chitwan.

\section{REFERENCES}

1. Gershy-Damet GM, Rotz P, Cross D, Belabbes el H, Cham F, Ndihokubwayo JB, et al. The World Health Organization African region laboratory accreditation process: improving the quality of laboratory systems in the African region. Am J Clin Pathol. 2010 Sep;134(3):393-400.

2. Khan MA, Khan FA. Low cost quality control human serum: method of preparation, validation of values and its comparison with the commercial control serum. J Pak Med Assoc. 2004 Jul;54(7):375-8.

3. Howanitz PJ, Tetrault GA, Steindel SJ. Clinical laboratory quality control: a costly process now out of control. Clin Chim Acta. 1997 Apr 25;260(2):163-74.

4. Hinckley CM. Defining the best quality-control systems by design and inspection. Clinical Chemistry. 1997 May 1, 1997;43(5):873-9.

5. Browning DM, Hill PG, Olazabal AVR. World Health Organization. Health Laboratory Technology Unit. Preparation of stabilized liquid quality control serum to be used in clinical chemistry. [Geneva]: World Health Organization; 1986.
6. Premachandra P, Wood PL, Hill PG, Browning DM, Olazabal DA. Preparation and stability of low-cost liquid quality-control serum stabilized with ethanediol. Clin Chem. 1987 Jun;33(6):851-2.

7. Levey S, Jennings ER. The use of control charts in the clinical laboratory. Am J Clin Pathol. 1950 Nov;20(11):1059-66.

8. Westgard JO, Groth T, Aronsson T, Falk H, de Verdier $\mathrm{CH}$. Performance characteristics of rules for internal quality control: probabilities for false rejection and error detection. Clin Chem. 1977 Oct;23(10):1857-67.

9. Peyret M, Flandrois JP, Carret G, Pichat C. [Interpretative reading and quality control of an antibiotic sensitivity test using an expert system. Application to the API ATB system and Enterobacteriaceae]. Pathol Biol (Paris). 1989 Jun;37(5 Pt 2):624-8.

10. Gyawali P, Lamsal N, Tamrakar S, Shrestha R, Aryal P, Raut B, et al. Quality assessment and good laboratory practice in clinical chemistry laboratory at diagnostic laboratories in Nepal. Clinical Biochemistry. 2011;44(13, Supplement):S4.

11. Mishra SK, Tiwari BR, Yadav BK. Status of pathology professionals. J Nepal Health Res Counc. 2012 Jan;10(1):37-40. 